\title{
Ectopic ACTH Syndrome
}

\begin{abstract}
Ectopic adrenocorticotropic secretion (EAS) is responsible for $12-17 \%$ of cases of Cushing's syndrome (CS) and covers a range of tumours, from undetectable benign lesions to widespread metastases. The syndrome is often associated with severe hypercortisolaemia, which aggravates the underlying condition. EAS requires a complete workup that includes the establishment of endogenous CS, diagnosis of adrenocorticotropic hormone (ACTH) dependency, localization of the source of ACTH secretion and rapid biochemical control of hypercortisolaemia. Dynamic endocrine tests should include inferior petrosal sinus sampling with $\mathrm{CRH}$ stimulation. Localization studies depend on the availability of reliable high-resolution cross-sectional imaging. This systematic review of the largest published series of patients with EAS (over 380 patients) reveals the common trends in the prevalence and management of this syndrome. The concept of 'occult' EAS has been revisited and the terms 'overt' and 'covert' EAS introduced. In addition to small cell lung carcinoma, the most common causes of ectopic EAS are bronchial carcinoids, thymic tumours, islet cell tumour of the pancreas, medullary thyroid carcinomas, and phaeochromocytomas. Their prevalence and the best localization modalities are presented. Medical and surgical management is discussed on the basis of the extensive experience of major referral centres. (Arq Bras Endocrinol Metab 2007;51/8:1217-1225)
\end{abstract}

Keywords: Cushing's syndrome; Ectopic; ACTH; Neuroendocrine tumours; Paraneoplastic

\section{RESUMO}

Síndrome do ACTH Ectópico.

A secreção ectópica de ACTH (SEA) é responsável por 12-17\% dos casos de síndrome de Cushing (SC), cobrindo uma variedade de tumores, desde lesões benignas indetectáveis a metástases disseminadas. A SEA está freqüentemente associada com hipercortisolemia grave, que agrava a condição de base e requer uma avaliação completa, que inclui a confirmação da SC endógena, o diagnóstico da dependência ao ACTH, a localização da fonte da secreção de ACTH e o controle bioquímico rápido da hipercortisolemia. Testes endócrinos dinâmicos devem incluir a coleta de amostras do seio petroso inferior com estímulo pelo $\mathrm{CRH}$. O estudo da localização da fonte depende da disponibilidade de procedimentos de imagem de alta-resolução confiáveis. A revisão sistemática das maiores séries publicadas de pacientes com SEA (mais de 380 pacientes) revela tendências comuns na prevalência e manejo dessa síndrome. O conceito de SEA “oculta" está sendo revisado e os termos SEA "manifesta" e "latente" são introduzidos. Além do carcinoma pulmonar de pequenas células, as causas mais comuns de SEA são os carcinóides brônquicos, tumores tímicos, tumor de ilhotas pancreáticas, carcinoma medular de tiróide e feocromocitoma; sua prevalência e as melhores modalidades para localização são apresentadas. O manejo clínico e cirúrgico é discutido com base na vasta experiência dos principais centros de referência. (Arq Bras Endocrinol Metab 2007;51/8:1217-1225)

Descritores: Síndrome de Cushing; ACTH ectópico; ACTH; Tumores neuroendócrinos; Paraneoplasia atualização

\author{
ANDREA M. ISIDORI \\ ANDREA LENZI
}

DFM - Department of

Pathophysiology, "Sapienza"

University of Rome, Italy. 


\section{OVERT AND OCCULT ECTOPIC ACTH SYNDROME}

$\mathrm{T}$ He association between cancer and Cushing's syndrome (CS) was first recognized in 1928 in a patient with oat cell carcinoma of the lung (1), but it was not until the 1960s that a connection was made between adrenocorticotropic hormone (ACTH)dependent CS and certain non-pituitary tumours (2). It later became evident that numerous types of endocrine and non-endocrine tumours acquire the ability to secrete substances that are not normally secreted from the tissue in which they originate. It is now well recognized that ectopic ACTH secretion (EAS), leading to endogenous CS, can be associated with various solid tumours, mostly of neuroendocrine origin (3). For clinical and diagnostic clarity the term EAS also includes a much rarer condition where CS is sustained by the ectopic production of other peptides, such as CRH and bombesin, which directly or indirectly stimulate the adrenal gland.

The diagnosis of suspected Cushing's syndrome involves three steps: confirmation of hypercortisolism, differentiation between adrenocorticotropin (ACTH)independent and ACTH-dependent causes of Cushing's syndrome, and differentiation between pituitary and ectopic (EAS) sources of ACTH (4). As correction of cortisol hypersecretion by the selective removal of a pituitary microadenoma or of a solitary bronchial carcinoid tumour has a high probability of resolving the condition, it is essential to distinguish EAS from the much more common Cushing's disease (CD) and, in the former, to make every effort to localize the source of ectopic ACTH $(5,6)$.

Various benign and malignant tumours have been associated with EA. In most cases, when EA is produced by malignant tumours, circulating ACTH and cortisol levels are extremely high, the duration of symptoms is short and the clinical phenotype is atypical, in comparison with pituitary-dependent CS. Conversely, EAS is often associated with a number of mainly neuroendocrine tumours with differing aggressiveness which produce the typical signs and symptoms of CS, with a biochemical resemblance to pituitary CD.

For this reason, it was suggested that a definitive diagnosis of EAS requires stringent criteria, including reversal of the clinical picture after resection of the tumour and/or demonstration of ACTH immunohistochemical staining in the tumour tissue. However, these criteria are not applicable to many of the reported cases of EAS (7). Tumour resection cannot be curative in disseminated tumours, nor can lack of staining in a biopsy specimen disprove EAS, as only a subpopulation of cells may actually secrete ACTH.

The term 'occult' EAS was introduced for those cases with unequivocal non-pituitary CS in which the source of ectopic ACTH secretion was not obvious (8). However, this term may no longer be suitable, as recent improvements in endocrine dynamic testing, cross-sectional imaging and the increasing focus on the earlier diagnosis of CS have progressively changed the clinical spectrum of patients investigated for EAS. We therefore recently proposed (9) a reclassification of EAS as overt, when the tumoral source is easily detected by the initial endocrine and radiological investigations, and covert, when it occurs in patients presenting with hypercortisolaemia where the ectopic source was not detected during initial tests, but was discovered on subsequent evaluation or during prolonged follow-up. Occult EAS is reserved for patients with features of CS for whom all tests indicate an ectopic source, but the primary lesion is not identified even after prolonged and repeated follow-up (10). Occult EAS is one of the most intriguing challenges for the clinical endocrinologist, as in some cases no tumour is found even after long-term follow-up - or at autopsy.

Patients are often treated with bilateral adrenalectomy to control hypercortisolaemia. Nevertheless, occult tumours can be malignant and metastasize, so regular follow-up visits should be performed. In addition, recent advances in imagining techniques are likely to reduce the number of patients with truly occult EAS, encouraging the use of adrenolytic drugs rather than definitive surgical removal of the adrenal glands. To what extent repeated serial scanning (CT and $\mathrm{RMI}$ ), novel imaging techniques (PET-CT), radionuclide investigation (octreoscan) or invasive diagnostic procedures (catheterization, surgical exploration, etc.) should be carried out in these patients or when to shift from adrenolytic drugs to adrenalectomy is often a difficult decision that must be made on a caseby-case basis.

Considering that EAS accounts for $10 \%$ to $20 \%$ of all cases of Cushing's syndrome, these syndromes constitute a small but significant percentage of patients presenting with clinical overt hypercortisolism $(4,7,9,11)$.

This review summarizes the findings of the largest published series of patients with EAS in order to highlight the procedures and therapeutic decisions most frequently adopted in the management of difficult cases. Although the reported series have substantial differences, the two most recent - from the NIH (11) and St. Bartholomew's Hospital of Lon- 
don (9) - share many similarities in their investigational protocols, results and conclusions. These findings are compared against other studies (12-18), with particular attention to the management of covert and occult tumours.

\section{THE SOURCE OF ACTH SECRETION}

Various tumours can cause EAS, especially those originating in neuroendocrine cells, which are capable of amine precursor uptake and decarboxylation (APUD) (7). Small cell lung carcinoma (SCLC), carcinoid tumours - especially of the lungs, thymus, and gastrointestinal tract - islet cell tumours, phaeochromocytoma, medullary thyroid carcinomas (MTC), are the most frequent (figure 1), along with a number of miscellaneous tumours (table 1 ) including paraganglioma, neuroblastoma, prostate, breast, kidney, stomach, ovary, melanoma, colon, leukaemia, and anorectal cancer that have all been associated with ectopic Cushing's syndrome (19).

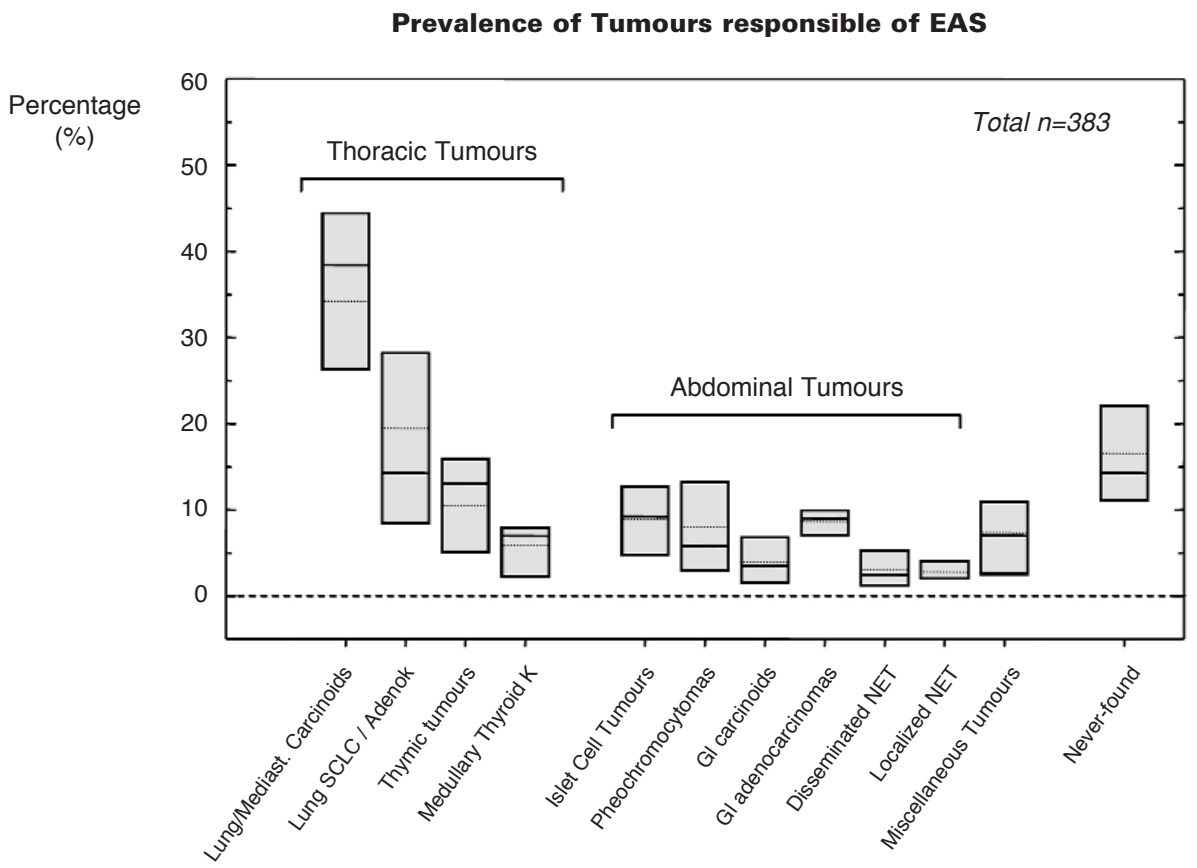

Figure 1. Distribution of the most frequent source (> $2 \%$ ) of ectopic ACTH secretion in a group of 383 patients with EAS syndrome based on the following published series: Aniszewski et al. (16), Findling et al. (13), Imura et al. (15), Doppman et al. (12), Howlett et al. (14), Ilias et al. (11), Isidori et al. (9), Salgado et al. (17).

Table 1. Tumours rarely associated with EAS. The frequency is calculated among all reported cases in literature.

\begin{tabular}{lll}
\hline & FREQUENCY 1-3\% & FREQUENCY $\leq \mathbf{1 \%}$ \\
Tumours associated with EAS & Ovarian carcinoma & Esophageal carcinoma \\
& Colonic/anal carcinoma & Kidney tumor \\
& Prostate & Hepatocarcinoma \\
& Uterine cervix carcinoma & Breast carcinoma \\
& Neuroblastoma & Salivary gland tumor \\
& & Mesothelioma \\
\hline \multirow{2}{*}{ [Ectopic pituitary adenoma] } & Lymphoma \\
& & Melanoma \\
& & Leydig cell tumor \\
& & Larynx carcinoma \\
& & Gallbladder tumours \\
\hline
\end{tabular}


In the past, small cell lung cancers (SCLC) accounted for most cases of EAS $(15,19)$. However, in recent surveys the preponderance of these tumours has been substantially reduced, in favour of other histological types $(8,20)$. Changing referral patterns are responsible for these differences. Chance or referral bias is also the probable cause of the marked difference in percentage distribution of the various neoplastic sources of ectopic ACTH in the published series. A summary of over 380 cases from the largest published series of ectopic Cushing's syndrome is given in figure 1. This gives a summary distribution - taking account of the known differences among the various series - generated by calculating the median and range of prevalence of various ectopic sources in the different series, in order to highlight the common trends. Single-case reports have been excluded, to avoid inflating the prevalence of rare causes of EAS through publication bias. Other, less common, miscellaneous tumours causing EAS are therefore presented separately in table 1 .

The analysis reveals that the lung is still the most likely organ to harbour an ectopic source of ACTH, being the origin of over $45 \%$ of tumours; most cases are bronchial carcinoid tumours (> 25\%) followed by SCLC or adenocarcinomas $(\sim 20 \%)$. For the first time, the frequency of bronchial carcinoids was higher than SCLC in the most recent series, demonstrating the change in referral patterns. When SCLCs were excluded from the analysis, the bronchial carcinoid frequency was as high as $32 \%$ of all cases of EAS.

The next most commonly reported tumours causing EAS were harboured in the thymus (11\%) and pancreas $(8 \%)$. Other sources were mostly related to tumours with neuroendocrine differentiation, such as medullary thyroid carcinomas (6\%) and adrenal phaeochromocytomas $(5 \%)$. Only $6-8 \%$ of histologically confirmed cases derived from non-endocrine, non-pulmonary tumours; these comprised ovarian carcinomas $(>2 \%)$, anorectal carcinomas $(2 \%)$ neuroblastoma ( $1 \%)$, uterine cervix carcinomas, prostate cancers a few more other tumours (table 1 ).

The main conclusion that can be drawn from the most recently published series $(9,11)$ is that more than half of the tumours causing EAS were found in the lung or in the thymus, while, when including medullary thyroid cancers (MTC) and phaeocromocytomas, $2 / 3$ were in the thorax, neck or adrenal glands. Only $1 / 3$ of primary tumours were found in the abdomen, most frequently in the pancreas $(8 \%)$ or the colon $(4 \%)$.

Although SCLC still remains one of the most common causes of EAS, only a minority of patients with SCLC - approximately 1.6-4.5\% - manifest overt hypercortisolaemia, and this is probably associated with increased comorbidity (21-23). In our series we found that such patients suffer from hypercortisolaemia-related complications such as pancreatitis, peritonitis, and septicaemia, and control of the excess cortisol is thus an important part of their management.

We also found that despite repeated evaluation and long term follow-up (up to 10 years), the source of EAS remains unidentified in a significant number of patients (12.5\%) (9). In the NIH series, this figure rises to $19 \%$, although the follow-up period was shorter (11). In other series the number of occult tumours ranges from 8 to $32 \%$. The progressively smaller figures seen in recent studies are the result of substantial improvements in imaging techniques.

It should be emphasized that the diagnosis of occult EAS, according to our definition, is made by exclusion, after prolonged investigation and long-term hypercortisolaemia control. In such cases, every effort should be made to localize the source of ectopic ACTH secretion, even if this requires several years, as previously unsuspected sources have been identified during autopsy.

\section{THE CLINICAL PRESENTATION OF EAS}

Describing the clinical signs and symptoms attributed to EAS from retrospective studies is occasionally difficult and may be misleading, as in many reports some signs and symptoms may not be specifically mentioned and the absence of expected signs and symptoms is not always addressed. Our single-site series has the advantage that relevant clinical information was collected on the basis of a consistent protocol in which specific signs and symptoms were assigned as either present or absent, thus eliminating variations in data accrual among the interviewing doctors (24). The clinical features of EAS patients in our series were quite wideranging, resembling those of $\mathrm{CD}$ patients even in some patients with SCLC $(8,19)$. It is likely that SCLC patients, when evaluated at an earlier stage, may present in a similar manner to patients with other, less malignant causes of EAS $(14,19)$. However, patients with SCLC more commonly present with skin pigmentation and absence of facial fullness or weight gain in comparison with other causes (9). The time between the first clinical symptom of hypercortisolism and diagnosis of ectopic Cushing's syndrome was shortest in patients with small cell bronchial carcinoma (3-4 months) and pancreatic islet cell tumours (6-8 
months), in contrast with bronchial carcinoids (6-24 months). In comparison with other neuroendocrine tumours, which present a classic Cushingoid appearance in nearly all cases, only $2 / 3$ of patients with small cell bronchial carcinoma showed the clinical signs (moon face and central obesity) of overt hypercortisolism (19). These differences are probably due to the rapidity of onset and the severity of the hypercortisolaemia. Clinicians should be aware that in a patient with rapidly advancing small cell lung cancer and deteriorating clinical condition, the development of ectopic Cushing's syndrome can pass undiagnosed, leading to significant additional comorbidity (22).

In contrast, no major differences were found between patients with occult and overt EAS. This suggests that tumour mass (and consequently detectability) is not necessarily a predictor for the tumour's secretory characteristics or the clinical features of the syndrome (9). A recent single-site study showed a relatively high incidence $(35 \%)$ of systemic infections in patients with EAS (25). In our series, although cortisol levels were similar to those encountered in previous studies, severe and/or life-threatening infections developed in about $15 \%$ of patients and were related to the degree of hypercortisolaemia. Hypokalaemia was present in $70 \%$ of our patients, and was again related to the degree of hypercortisolaemia $(14,19,26)$. In both the NIH and our series, a high prevalence (around 50\%) of psychiatric disorders was described $(9,11)$; we found that these symptoms were a distinctive feature of neuroendocrine tumours hypersecreting ACTH, in comparison with SCLC, where pigmentation was more prominent. A further recent finding is that up to $50 \%$ of patients with EAS may present osteoporosis or fractures (11).

The ectopic production of multiple hormones by a single tumour has been reported with increasing frequency in recent decades. Multiple secretion is a typical feature of tumours with neuroendocrine differentiation, especially islet cell tumours and medullary thyroid carcinomas. However, our analysis revealed that calcitonin and gastrin were the most commonly elevated tumour markers, regardless of tumour type. In the most recent series of EAS patients $(9,11)$, a variety of tumour markers were measured; however, they were proven to be of specific diagnostic value only in MCTs (calcitonin) and phaeochromocytomas (urinary catecholamines). In contrast, 5-HIAA levels were normal in the majority of patients, as neuroendocrine tumours arising from the embryonic foregut are usually deficient in the enzyme aromatic L-amino acid decarboxylase, therefore producing less serotonin but with a greater tendency to the peptide hormone production causing EAS (27).

\section{DIAGNOSIS OF ECTOPIC ACTH SECRETION}

Differential diagnosis criteria and pitfalls in the diagnosis of Cushing's syndrome are extensively discussed elsewhere in this issue. For the purposes of this review, the major conclusions drawn from the analysis of the largest published series are briefly summarised. Patients with EAS tend to have higher ACTH levels than those with $\mathrm{CD}$, but there is no clear distinction between the two groups. Bilateral inferior petrosal sinus sampling (BIPSS) is considered the gold standard for differential diagnosis. Tumours causing EAS are usually characterized by their unresponsiveness to glucocorticoid feedback, CRH or desmopressin responsiveness $(4,28)$. However, $22-40 \%$ of EAS patients demonstrate either serum or urinary 17OHCS suppression on the high-dose dexamethasone suppression test (HDDST) $(14,19)$. We recommend using serum rather than urinary cortisol or 17-OHCS as an indicator of adequate suppression, as this gives a much higher sensitivity $(3,4)$. All published series confirm that patients with bronchial carcinoids can show a significant degree of cortisol suppression (approximately $60 \%$ ) following the HDDST $(4,19)$. Variations of the formal HDDST failed to improve its performance (29).

Similarly, approximately $10-15 \%$ of patients with EAS have been shown to respond to $\mathrm{CRH}$ administration, regardless of various improved cut-off criteria for cortisol and/or ACTH $(3,4,30)$. In our series desmopressin stimulation, alone or in combination with $\mathrm{CRH}$, did not substantially improve the test's sensitivity or specificity. In fact, recent studies have found the $\mathrm{CRH}$ test to show a higher diagnostic accuracy than the HDDST (4,31-34). Our conclusion is that while each test on its own may be of relatively limited diagnostic accuracy, their combination may aid the diagnosis of EAS, with a sensitivity of $100 \%$ and a diagnostic accuracy of $98 \%(4,9,35)$. The combination of the various dynamic non-invasive endocrine tests can be extremely helpful in difficult cases and should be considered when the clinical, biochemical and/or radiological findings are not consistent with the results obtained from the BIPSS (4).

Regarding the accuracy of BIPSS, it should be remembered that although false positives (suggestive of CD) do undoubtedly occur, they are extremely rare $(<1 \%)$, and a positive BIPSS is a very strong indicator 
of CD. However, false negatives with BIPSS are more common than previously appreciated $(2-4 \%)$ and a negative BIPSS does not necessarily rule out a pituitary source of ACTH secretion, as at least 30 patients with documented false-negative results have been described (5,36-40). In our previous analysis we found a significant incidence of false negatives with BIPSS (3\%) (4). We conclude that while BIPSS is extremely helpful and a positive response is very highly suggestive (but not pathognomonic) of $\mathrm{CD}$, a negative response requires a careful search for an ectopic source, and dynamic tests should be performed to obtain further useful information.

\section{LOCALIZATION OF THE ACTH SECRETING TUMOUR}

After biochemical confirmation of EAS, optimal treatment includes localization and removal of the ACTHsecreting tumour $(28,34)$. Early detection of ectopic corticotropin-producing tumours is crucial in the management of affected patients, as it can avoid adrenalectomy and help to reduce the risk of metastatic disease. Localization of these tumours can occasionally be difficult and may require extensive long-term follow-up $(3,6)$. The application of an imaging protocol with reliable and high sensitivity procedures is advised.

Most SCLCs are detected using plain chest X ray, CT and/or MR imaging $(8,19,23)$. Bronchial carcinoids can be relatively small and thus be missed with conventional imaging; however, early application of 2-3 mm high-resolution CT chest scans, particularly with the new generation of multidetector CT, identifies the vast majority of such cases (41). According to series from other specialized centres, serial CT and MRI scans fail to localize around $33 \%$ to $44 \%$ of ectopic corticotropin-producing tumours $(12,13,42)$. In our series, CT and/or MRI failed to localize the ACTH-secreting tumours in approximately $12.5 \%$ of EAS cases; this is fewer than reported in previous studies and may be related to the prolonged follow-up and subsequent application of newer imaging techniques $(19,42)$. It has been advocated that in such cases imaging with ${ }^{111}$ In-octreotide can identify true occult ACTH-secreting tumours in most patients with NETs, including bronchial carcinoid tumours (43), as bronchial lesions less than $1 \mathrm{~cm}$ in diameter have been identified with this technique (19). However, there has been some concern whether it is really superior to CT scanning, as in a direct comparison ${ }^{111} \mathrm{In}$ octreotide identified fewer lesions than CT (44), and did not identify any tumours that were not also seen with CT $(19,42,44)$. In the most recently published series, scintigraphy with ${ }^{111}$ In-octreotide did not add to the diagnostic information derived from other imaging techniques. There is currently no consensus as to whether ${ }^{111}$ In-octreotide scintigraphy, after failing to establish the diagnosis at first presentation, should be included in the follow-up. We believe that there is insufficient data to exclude this examination, as it can still provide useful diagnostic information - other than mere localization - for the management of these patients $(45,46)$.

Pancreatic islet cell tumours and MTCs associated with EAS are usually large and have already metastasized to the liver by the time CS is diagnosed; no covert EAS secondary to an islet cell tumour was encountered in a relevant review (19). Such tumours are usually functional and co-secrete other biologically active substances associated with characteristic clinical syndromes, and CS is only occasionally the main complaint on presentation (19).

Positron emission tomography (PET) and PETCT have been proposed as potential imaging techniques for endocrine oncology. However, in a small published series, PET failed to detect tumours that were occult to traditional CT/MRI (47). Therefore in patients with EAS, PET remains a complementary imaging tool, for use only when other imaging techniques fail to characterize the $\mathrm{ACTH}$-secreting tumour.

Whole body catheterization studies (selective venous sampling from suspected sources of ectopic ACTH secretion) is technically difficult and of limited overall value in revealing unsuspected lesions $(12,19,48)$. As for dynamic testing, a single imaging study may give a false positive and it is therefore strongly recommended that CT, MRI, octreotide scanning (and perhaps in the future PET scans) are used together to localize the source of ectopic ACTH. Again, EAS is a condition requiring the collaboration of experts in a multi-disciplinary approach, preferably with a pre-defined protocol.

\section{MANAGEMENT OF EAS}

Once a single source has been located, the optimal management is surgical excision. Based on recently published series this can be achieved with a curative intent in up to $40 \%$ of patients with EAS, and is associated with complete remission in more than $80 \%$ of cases (9). There is a trend towards an increase in the 
proportion of patients cured of EAS: the 2001 Mayo Clinic series reports $12 \%$ curative resection, while the 2005 series at the NIH achieved 29\% (16). Although these figures may reflect differences in the prevalence of aggressive and disseminated tumours, awareness of the condition allows earlier diagnosis and a better outcome. It is essential that all patients with EAS receive treatment with one or more adrenolytics to restore eucortisolaemia as soon as the preliminary dynamic tests are completed. Ketoconazole and metyrapone are preferred for their efficacy and safety. Metyrapone is generally the first drug used, due to its rapid therapeutic onset. Treatment with glucocorticoid synthesis inhibitors should ideally be commenced prior to cytotoxic chemotherapy (8), but the dose may soon require titration or the addition of an adequate steroid replacement (block and replace regimen). Somatostatin and dopamine agonists have been used occasionally with good results, as some ACTH-producing tumours can express these receptors, but their role remains that of an adjuvant treatment $(49,50)$.

In the NIH series, infections were present in $51 \%$ of patients with EAS. In cases where long-term drug control of hypercortisolaemia is unsatisfactory or contraindicated and in women with occult EAS who wish to become pregnant, bilateral adrenalectomy can be used to resolve hypercortisolaemia (8). This procedure was required in $37 \%$ of our cases and $30 \%$ of cases in the NIH series. Global experience with the less invasive laparoscopic adrenalectomy has significantly changed the balance of risks associated with surgery and provides fast, effective control of hypercortisolaemia, especially in patients with aggressive tumours. Alternatively, when metyrapone and ketoconazole are ineffective in severely ill adults $(51,52)$ and children (53), etomidate infusion combined with hydrocortisone therapy can stabilize cortisol levels and is safe for the short-term preoperative control of severe hypercortisolaemia (10).

Patients with occult EAS sooner or later undergo adrenalectomy to achieve a biochemical cure, as it may take up to 10 or 20 years before the source is identified. These patients need life-long follow-up with serial imaging studies to detect early tumours that, albeit of low grade, might be malignant.

Advances in medical and surgical treatments have improved the overall survival rate of EAS patients, whose prognosis is however still a function of the primary tumour histology. In all series, patients with SCLC had the worst prognosis, usually dying within 12 months of diagnosis (median 6-8 months). Patients with bronchial carcinoids had the best prog- nosis, compared with patients affected by other tumours with neuroendocrine differentiation. Thymic tumours and phaeochromocytomas carried an intermediate prognosis. Islet cell tumours and MCT were aggressive and frequently metastatic at the time of diagnosis. The presence of metastatic deposits is another important predictor of overall survival. The survival of patients with an occult source of ACTH, but adequate control of hypercortisolaemia, was very $\operatorname{good}(9)$.

\section{CONCLUSIONS AND REMARKS}

Approximately $15-20 \%$ of patients with endogenous CS harbour a non-pituitary tumour responsible for ectopic ACTH secretion. The significant differences observed in the findings of previously published series of EAS patients became less marked in the most recent reports, documenting the syndrome's universal recognition and a common trend in management and results $(9,11)$. The first message that can be drawn is that nearly any neuroendocrine or non-endocrine tumour, including atypical tumours, may be associated with EAS. However, bronchial carcinoid tumours are the commonest cause of EAS, mainly presenting with classic signs and symptoms of CS. Thymic tumours, medullary thyroid carcinomas, phaeocromocytomas and islet cell tumours are the next most frequent sources of EAS. In advanced tumours, the features of hypercortisolaemia may be masked by a general deterioration in clinical condition and interpreted as a progression of the neoplastic disease; failure to recognize EAS can carry additional morbidity. EAS can occur at any stage of the disease: as the first presenting symptom or several years after diagnosis. The size of the tumour does not correlate with the severity of symptoms, nor are ACTH levels correlated with its aggressiveness. This survey shows that no single endocrine test - even dynamic and invasive tests - is accurate enough to distinguish ectopic from pituitary sources of ACTH hypersecretion in every case. However, there is a general consensus that the BIPSS, when performed by a skilled team in referral centres, remains the gold standard to confirm pituitary ACTH hypersecretion (although its diagnostic accuracy is lower than previously thought). In contrast, a single HDDST is insufficient for differential diagnosis.

Once EAS is suspected, high-resolution crosssectional imaging is now the technique of choice, as it is the best approach to localise the source of ectopic ACTH. Selective vein catheterization and radionuclide 
imaging are helpful only in selected cases. Rather than finding the source of EAS, their role is to provide additional information on the nature of the lesions identified with cross-sectional imaging.

Recent studies confirm that the combined efforts of the endocrinologist and expert radiologist enable the majority of lesions to be identified during initial investigations or at follow-up. In contrast with past unsatisfactory results, a curative surgical attempt should now be possible in more than $40 \%$ of patients with EAS, with complete remission anticipated in more than $80 \%$. Alternatively, when adequate control of hypercortisolaemia can be achieved with adrenolytic drugs, we suggest a wait-and-see approach, to avoid irreversible procedures associated with significant morbidity.

In the past, a significant number of patients with clear biochemical test discrepancies and no radiologically evident tumour were considered to have CD and underwent TSS. We believe that this is no longer an evidence-based approach: it is necessary to establish a diagnostic protocol based on recent published data, modern imaging techniques and a combination of dynamic tests $(4,36)$ and apply it to EAS patients who fail to demonstrate a lesion after meticulous investigations (10). Long-term follow-up may be necessary before a covert tumour causing EAS becomes detectable, especially through the ongoing improvement in imagining techniques. There is an everincreasing number of EAS case reports in which the "occult" tumour is eventually found years after bilateral adrenalectomy.

Independently of the cause of EAS, hypercortisolaemia must be adequately controlled as soon as the diagnosis is established. In a conservative approach, medical treatment can be prolonged for years with good tolerability while awaiting tumour localization. Bilateral adrenalectomy is an alternative to long-term adrenolytic medication in patients with disseminated tumours or with special needs or contraindications to these drugs.

Bone fractures, infections, and thrombosis are serious frequent complications in patients with EAS. In recent series, long-term survival has been obtained even in patients with disseminated NETs. CS can occasionally be fulminating; in this case, emergency bilateral adrenalectomy is the only option. In these patients, etomidate can be used intravenously to control hypercortisolaemia (5l). Finally, whenever surgery is not curative, a multidisciplinary approach should be adopted including chemotherapy, radiotherapy, hormone analogues and/or radionuclide treatment to control tumour growth and associated symptoms.

\section{REFERENCES}

1. Brown WH. A case of pluriglandular syndrome. "Diabetes of bearded women". Lancet 1928;2:1022-3.

2. Liddle GW, Nicholson WE, Island DP, Orth DN, Abe K, Lowder SC. Clinical and laboratory studies of ectopic humoral syndromes. Recent Prog Horm Res 1969; 25:283-314.

3. Newell-Price J, Trainer P, Besser M, Grossman A. The diagnosis and differential diagnosis of Cushing's syndrome and pseudo-Cushing's states. Endocr Rev 1998;19:647-72.

4. Isidori AM, Kaltsas GA, Mohammed S, Morris DG, Jenkins P, Chew SL, et al. Discriminatory value of the low-dose dexamethasone suppression test in establishing the diagnosis and differential diagnosis of Cushing's syndrome. J Clin Endocrinol Metab 2003;88:5299-306.

5. Kaltsas GA, Giannulis MG, Newell-Price JD, Dacie JE, Thakkar $C$, Afshar $F$, et al. A critical analysis of the value of simultaneous inferior petrosal sinus sampling in Cushing's disease and the occult ectopic adrenocorticotropin syndrome. J Clin Endocrinol Metab 1999;84:487-92.

6. Raff H, Findling JW. A physiologic approach to diagnosis of the Cushing syndrome. Ann Intern Med 2003;138:980-91.

7. Baylin SB, Mendelsohn G. Ectopic (inappropriate) hormone production by tumors: mechanisms involved and the biological and clinical implications. Endocr Rev 1980;1:45-77.

8. Wajchenberg $\mathrm{BL}$, Mendonça BB, Liberman B, Pereira MA, Carneiro PC, Wakamatsu A, et al. Ectopic adrenocorticotropic hormone syndrome. Endocr Rev 1994;15:752-87.

9. Isidori AM, Kaltsas GA, Pozza C, Frajese V, Newell-Price J, Reznek RH, et al. The Ectopic Adrenocorticotropin Syndrome: clinical features, diagnosis, managment and long-term follow-up. J Clin Endocrinol Metab 2006;91:371-7.

10. Isidori AM, Kaltsas GA, Grossman AB. Ectopic ACTH syndrome. Front Horm Res 2006;35:143-56.

11. Ilias I, Torpy DJ, Pacak K, Mullen N, Wesley RA, Nieman LK. Cushing's syndrome due to ectopic corticotropin secretion: twenty years' experience at the National Institutes of Health. J Clin Endocrinol Metab 2005;90:4955-62.

12. Doppman JL, Nieman L, Miller DL, Pass HI, Chang R, Cutler $\mathrm{GB}$, Jr., et al. Ectopic adrenocorticotropic hormone syndrome: localization studies in 28 patients. Radiology 1989; 172:115-24.

13. Findling JW, Tyrrell JB. Occult ectopic secretion of corticotropin. Arch Intern Med 1986;146:929-33.

14. Howlett TA, Drury PL, Perry L, Doniach I, Rees LH, Besser GM. Diagnosis and management of ACTH-dependent Cushing's syndrome: comparison of the features in ectopic and pituitary ACTH production. Clin Endocrinol (Oxf) 1986;24:699-713.

15. Imura H, Matsukura S, Yamamoto H, Hirata Y, Nakai Y. Studies on ectopic ACTH-producing tumors. II. Clinical and biochemical features of 30 cases. Cancer 1975;35:1430-7.

16. Aniszewski JP, Young WF, Jr., Thompson GB, Grant CS, van Heerden JA. Cushing syndrome due to ectopic adrenocorticotropic hormone secretion. World J Surg 2001;25:934-40.

17. Salgado LR, Fragoso MC, Knoepfelmacher M, Machado MC, Domenice S, Pereira MA, et al. Ectopic ACTH syndrome: our experience with 25 cases. Eur J Endocrinol 2006;155:725-33.

18. Hernandez I, Espinosa-de-los-Monteros AL, Mendoza V, Cheng S, Molina M, Sosa E, et al. Ectopic ACTH-secreting syndrome: a single center experience report with a high prevalence of occult tumor. Arch Med Res 2006;37:976-80.

19. Beuschlein F, Hammer GD. Ectopic pro-opiomelanocortin syndrome. Endocrinol Metab Clin North Am 2002; 31:191-234.

20. Limper AH, Carpenter PC, Scheithauer B, Staats BA. The Cushing syndrome induced by bronchial carcinoid tumors. Ann Intern Med 1992; 117:209-14.

21. Shepherd FA, Laskey J, Evans WK, Goss PE, Johansen E, Khamsi F. Cushing's syndrome associated with ectopic corticotropin production and small-cell lung cancer. J Clin Oncol 1992;10:21-7.

22. Orth DN. Cushing's syndrome. N Engl J Med 1995; 332:791-803. 
23. Delisle L, Boyer MJ, Warr D, Killinger D, Payne D, Yeoh JL, et al. Ectopic corticotropin syndrome and small-cell carcinoma of the lung. Clinical features, outcome, and complications. Arch Intern Med 1993; 153:746-52.

24. Trainer PJ, Besser GM, St. Bartholomew's H. The Bart's endocrine protocols. Edinburgh: Churchill Livingstone, 1995.

25. Sarlis NJ, Chanock SJ, Nieman LK. Cortisolemic indices predict severe infections in Cushing syndrome due to ectopic production of adrenocorticotropin. J Clin Endocrinol Metab 2000;85:42-7.

26. Putignano $P$, Kaltsas GA, Korbonits $M$, Jenkins PJ, Monson $J P$, Besser GM, et al. Alterations in serum protein levels in patients with Cushing's syndrome before and after successful treatment. J Clin Endocrinol Metab 2000;85:3309-12.

27. Van Sickle DG. Carcinoid tumors. Analysis of 61 cases, including 11 cases of carcinoid syndrome. Cleve Clin $\mathbf{Q}$ 1972;39:79-86.

28. Newell-Price J, Grossman A. Diagnosis and management of Cushing's syndrome. Lancet 1999; 353:2087-8.

29. Kaye TB, Crapo L. The Cushing syndrome: an update on diagnostic tests. Ann Intern Med 1990; 112:434-44.

30. Nieman LK, Oldfield EH, Wesley R, Chrousos GP, Loriaux DL, Cutler GB, Jr. A simplified morning ovine corticotropinreleasing hormone stimulation test for the differential diagnosis of adrenocorticotropin-dependent Cushing's syndrome. J Clin Endocrinol Metab 1993;77:1308-12.

31. Newell-Price J, Morris DG, Drake WM, Korbonits M, Monson $J P$, Besser GM, et al. Optimal response criteria for the human $\mathrm{CRH}$ test in the differential diagnosis of ACTH-dependent Cushing's syndrome. J Clin Endocrinol Metab 2002; 87:1640-5.

32. Reimondo G, Paccotti $P$, Minetto M, Termine A, Stura G, Bergui $\mathrm{M}$, et al. The corticotrophin-releasing hormone test is the most reliable noninvasive method to differentiate pituitary from ectopic ACTH secretion in Cushing's syndrome. Clin Endocrinol (Oxf) 2003;58:718-24.

33. Aron DC, Raff H, Findling JW. Effectiveness versus efficacy: the limited value in clinical practice of high dose dexamethasone suppression testing in the differential diagnosis of adrenocorticotropin-dependent Cushing's syndrome. J Clin Endocrinol Metab 1997;82:1780-5.

34. Findling JW, Raff H. Diagnosis and differential diagnosis of Cushing's syndrome. Endocrinol Metab Clin North Am 2001;30:729-47.

35. Nieman LK, Chrousos GP, Oldfield EH, Avgerinos PC, Cutler $\mathrm{GB}$, Jr., Loriaux DL. The ovine corticotropin-releasing hormone stimulation test and the dexamethasone suppression test in the differential diagnosis of Cushing's syndrome. Ann Intern Med 1986; 105:862-7.

36. Swearingen B, Katznelson L, Miller K, Grinspoon S, Waltman A, Dorer DJ, et al. Diagnostic errors after inferior petrosal sinus sampling. J Clin Endocrinol Metab 2004;89:3752-63.

37. Zarrilli L, Colao A, Merola B, La Tessa G, Spaziante R, Tripodi FS, et al. Corticotropin-releasing hormone test: improvement of the diagnostic accuracy of simultaneous and bilateral inferior petrosal sinus sampling in patients with Cushing syndrome. World J Surg 1995;19:150-3.

38. McNally PG, Bolia A, Absalom SR, Falconer-Smith J, Howlett TA. Preliminary observations using endocrine markers of pituitary venous dilution during bilateral simultaneous inferior petrosal sinus catheterization in Cushing's syndrome: is combined CRF and TRH stimulation of value? Clin Endocrinol (Oxf) 1993; 39:681-6.

39. Bonelli FS, Huston J, III, Carpenter PC, Erickson D, Young WF, Jr., Meyer FB. Adrenocorticotropic hormone-dependent Cushing's syndrome: sensitivity and specificity of inferior petrosal sinus sampling. AJNR Am J Neuroradiol 2000; 21:690-6.

40. Colao A, Faggiano A, Pivonello R, Giraldi FP, Cavagnini F, Lombardi G. Inferior petrosal sinus sampling in the differential diagnosis of Cushing's syndrome: results of an Italian multicenter study. Eur J Endocrinol 2001;144:499-507.
41. Shrager JB, Wright CD, Wain JC, Torchiana DF, Grillo HC, Mathisen DJ. Bronchopulmonary carcinoid tumors associated with Cushing's syndrome: a more aggressive variant of typical carcinoid. J Thorac Cardiovasc Surg 1997 114:367-75.

42. Torpy DJ, Chen CC, Mullen N, Doppman JL, Carrasquillo JA, Chrousos GP, et al. Lack of utility of (111)In-pentetreotide scintigraphy in localizing ectopic ACTH producing tumors: follow-up of 18 patients. J Clin Endocrinol Metab 1999; 84:1186-92.

43. De Herder WW, Lamberts SW. Octapeptide somatostatinanalogue therapy of Cushing's syndrome. Postgrad Med J 1999;75:65-6.

44. Tabarin A, Valli N, Chanson P, Bachelot $Y$, Rohmer V, BexBachellerie $V$, et al. Usefulness of somatostatin receptor scintigraphy in patients with occult ectopic adrenocorticotropin syndrome. J Clin Endocrinol Metab 1999; 84:1193-202.

45. Tsagarakis S, Christoforaki M, Giannopoulou H, Rondogianni F, Housianakou I, Malagari C, et al. A reappraisal of the utility of somatostatin receptor scintigraphy in patients with ectopic adrenocorticotropin Cushing's syndrome. J Clin Endocrinol Metab 2003;88:4754-8.

46. Fanti S, Farsad M, Battista G, Monetti F, Montini GC, Chiti A, et al. Somatostatin receptor scintigraphy for bronchial carcinoid follow-up. Clin Nucl Med 2003;28:548-52.

47. Pacak K, Ilias I, Chen CC, Carrasquillo JA, Whatley M, Nieman LK. The role of [(18)F]fluorodeoxyglucose positron emission tomography and [(111)In]-diethylenetriaminepentaacetate-DPhe-pentetreotide scintigraphy in the localization of ectopic adrenocorticotropin-secreting tumors causing Cushing's syndrome. J Clin Endocrinol Metab 2004;89:2214-21.

48. Doppman JL, Pass HI, Nieman LK, Miller DL, Chang R, Cutler $\mathrm{GB}$, Jr., et al. Corticotropin-secreting carcinoid tumors of the thymus: diagnostic unreliability of thymic venous sampling. Radiology 1992:184:71-4.

49. Hearn PR, Reynolds $C L$, Johansen $K$, Woodhouse NJ. Lung carcinoid with Cushing's syndrome: control of serum ACTH and cortisol levels using SMS 201-995 (sandostatin). Clin Endocrinol (Oxf) 1988;28:181-5.

50. Pivonello R, Ferone D, Lamberts SW, Colao A. Cabergoline plus lanreotide for ectopic Cushing's syndrome. N Engl J Med 2005;352:2457-8.

51. Drake WM, Perry LA, Hinds CJ, Lowe DG, Reznek RH, Besser GM. Emergency and prolonged use of intravenous etomidate to control hypercortisolemia in a patient with Cushing's syndrome and peritonitis. J Clin Endocrinol Metab 1998 83:3542-4.

52. Krakoff J, Koch CA, Calis KA, Alexander RH, Nieman LK. Use of a parenteral propylene glycol-containing etomidate preparation for the long-term management of ectopic Cushing's syndrome. J Clin Endocrinol Metab 2001;86:4104-8.

53. Greening JE, Brain CE, Perry LA, Mushtaq I, Sales MJ, Grossman $A B$, et al. Efficient short-term control of hypercortisolaemia by low-dose etomidate in severe paediatric Cushing's disease. Horm Res 2005; 64:140-3.

Address for correspondence:

Andrea M. Isidori

DFM - Department of Pathophysiology

"Sapienza" University

00161 Rome, Italy

Fax: + 39064455345

E-mail: andrea.isidori@uniroma 1.it 